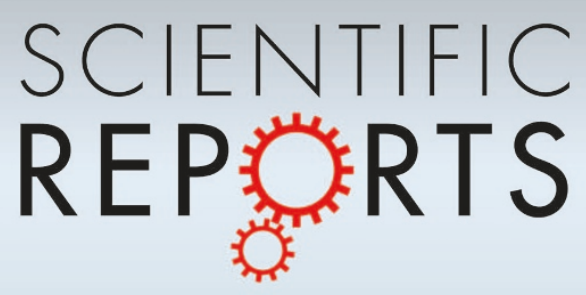

SUBJECT AREAS:

CATALYST SYNTHESIS

SYNTHESIS OF GRAPHENE

PHOTOCATALYSIS

ELECTROCATALYSIS

Received

3 May 2013

Accepted

1 July 2013

Published

23 July 2013

Correspondence and requests for materials should be addressed to N.P. (noejung@unist. ac.kr); L.D. (liming. dai@case.edu) or J.-B.B. (jbbaek@unist. ac.kr)

* These authors contributed equally to this work.

\section{Direct nitrogen fixation at the edges of graphene nanoplatelets as efficient electrocatalysts for energy conversion}

\author{
In-Yup Jeon ${ }^{*}$, Hyun-Jung Choi ${ }^{*}$, Myung Jong Ju'*, In Taek Choi ${ }^{2}$, Kimin Lim ${ }^{3}$, Jaejung Ko ${ }^{3}$, \\ Hwan Kyu Kim², Jae Cheon Kim', Jae-Joon Lee ${ }^{4}$, Dongbin Shin', Sun-Min Jung', Jeong-Min Seo', \\ Min-Jung Kim ', Noejung Park', Liming Dai ${ }^{1,5}$ \& Jong-Beom Baek'
}

\begin{abstract}
'Ulsan National Institute of Science and Technology (UNIST), Interdisciplinary School of Green Energy/Low-Dimensional Carbon Materials Center, Ulsan 689-897, South Korea, ${ }^{2}$ Global GET-Future Laboratory/Department of Advanced Materials Chemistry, Korea University, Sejong 339-700, South Korea, ${ }^{3}$ Photovoltaic Materials/Department of Advanced Materials Chemistry, Sejong 339-700, South Korea, ${ }^{4}$ Department of Applied Chemistry, Konkuk University, Chungiu 380-701, South Korea, ${ }^{5}$ Department of Macromolecular Science and Engineering, Case Western Reserve University, 10900 Euclid Avenue, Cleveland, Ohio 44 106, USA.
\end{abstract}

Nitrogen fixation is essential for the synthesis of many important chemicals (e.g., fertilizers, explosives) and basic building blocks for all forms of life (e.g., nucleotides for DNA and RNA, amino acids for proteins). However, direct nitrogen fixation is challenging as nitrogen $\left(\mathrm{N}_{2}\right)$ does not easily react with other chemicals. By dry ball-milling graphite with $\mathrm{N}_{2}$, we have discovered a simple, but versatile, scalable and eco-friendly, approach to direct fixation of $\mathrm{N}_{2}$ at the edges of graphene nanoplatelets ( $\left.\mathrm{GnPs}\right)$. The mechanochemical cracking of graphitic $\mathrm{C}-\mathrm{C}$ bonds generated active carbon species that react directly with $\mathrm{N}_{2}$ to form fiveand six-membered aromatic rings at the broken edges, leading to solution-processable edge-nitrogenated graphene nanoplatelets ( $\mathrm{NGnPs}$ ) with superb catalytic performance in both dye-sensitized solar cells and fuel cells to replace conventional Pt-based catalysts for energy conversion.

$\mathrm{N}$ itrogen $\left(\mathrm{N}_{2}\right)$ fixation is essential for the manufacture of fertilizer and explosives (e.g., gunpowder, TNT) as well as the biosynthesis of basic building blocks for all forms of life (e.g., nucleotides for DNA and RNA, amino acids for proteins) ${ }^{1}$. However, $\mathrm{N}_{2}$, the most abundant constituent in air, is normally considered to be inert diatomic gas due to the extremely strong triple bond. As a result, there are only a few of chemical/biological processes to convert the nitrogen gas into other compounds. While nitrogen is reduced into ammonia in the root nodules of plants ${ }^{2}$, the Haber process to convert nitrogen into ammonia involves the use of an iron oxide $\left(\mathrm{Fe}_{3} \mathrm{O}_{4}\right)$ catalyst in the presence of hydrogen under extremely harsh conditions of about $500^{\circ} \mathrm{C}$ and $200 \mathrm{~atm}^{3}$. Likewise, graphite with the planar layered structure is the most thermodynamically stable form of carbon allotropes. Hence, it is an extreme challenge for the $\mathrm{C}-\mathrm{N}$ bond formation directly from graphite and $\mathrm{N}_{2}$. Based on our recent work on the direct $\mathrm{C}-\mathrm{C}$ bond formation between graphite and carbon dioxide $\left(\mathrm{CO}_{2}\right)$ by dry ball-milling in a sealed crusher ${ }^{4}$, we demonstrated in the present study the direct $\mathrm{N}_{2}$ fixation at the broken edges of graphitic frameworks by dry ball-milling graphite in the presence of $\mathrm{N}_{2}$ gas. The nature of the edge-functionalization by the dry ball-milling has been amply established in our previous study $y^{4,5}$.

On the other hand, the search for economically viable alternatives to fossil fuels has attracted even increased attention among energy communities due to the continuously increasing energy price and global warming. Solar cells (SCs) and fuel cells (FCs) are considered to be promising alternatives. Although platinum (Pt)-based electrodes have been known to be the most efficient catalysts for dye-sensitized solar cells (DSSCs) ${ }^{6}$ and proton exchange membrane fuel cells (PEMFCs) ${ }^{7}$, they are too expensive and too susceptible to aggregation ${ }^{8}$ and poisoning impurities ${ }^{9}$ for practical applications. Recently, much effort has been devoted to reduce or replace Pt-based electrodes. In particular, heteroatom-doped carbon-based materials, such as carbon black ${ }^{10}$, carbon nanoparticles ${ }^{11}$, carbon nanotubes ${ }^{12,13}$ and graphene nanoplatelets ${ }^{14-17}$, have been intensively studied as metal-free catalysts. However, the commonly used chemical vapor deposition (CVD ${ }^{18}$ and/or Hummers' methods ${ }^{19}$ for the production of carbon nanotubes and graphene are either too expensive for practical applications or involving environmentally hazardous reagents. Therefore, the full potential of these carbon-based metal-free catalysts is hard to achieve without scalable production at low cost, though the basic catalytic mechanism has been 
established ${ }^{20}$. The large quantity of the edge-nitrogenated graphene nanoplatelets (NGnPs) produced through such a simple, low-cost, and eco-friendly ball-milling process were further demonstrated to be effective metal-free catalysts for the replacement of precious Ptbased catalysts in DSSCs and PEMFCs for energy conversion. Therefore, the approach developed in this study can be regarded as a versatile technique toward multifunctional carbon nanomaterials of practical significance.

\section{Results}

As schematically shown in Fig. 1a, the ball-milling-induced direct nitrogen fixation at the broken edges of graphitic frameworks involves the breakage of large grain size of graphite (Fig. 1b) into small ones (Fig. 1c). The cleavage of graphitic $\mathrm{C}-\mathrm{C}$ bonds by ballmilling created active carbon species to react with nitrogen, as shown in Fig. S1 (Electronic Supplementary Information, ESI). Thermodynamically, the most preferred edge formation of NGnPs is to maintain the aromaticity. The calculated binding energies $(\delta \mathrm{E})$ of nitrogen onto the zigzag-shaped and armchair-shaped broken edges were $-2.50 \mathrm{eV} / \mathrm{N}_{2}\left(-57.65 \mathrm{kcal} / \mathrm{N}_{2} \mathrm{~mol}\right)$ (Fig. 1d) and $-1.96 \mathrm{eV} / \mathrm{N}_{2}$ $\left(-45.20 \mathrm{kcal} / \mathrm{N}_{2} \mathrm{~mol}\right)$ (Fig. 1e), respectively, indicating an exothermic (spontaneous) reaction to form nitrogenated aromatic rings at the broken edges. Both aromatic 5-membered pyrazole and 6membered pyridazine rings could form at the edges of NGnPs via the zigzag and armchair cracking, respectively (Fig. S1). The unreacted residual active carbon species could be terminated by air moisture upon opening the lid as judged by violent sparkling
(Supplementary Video), leading to the formation of some oxygenated groups at the edges (Figs. 1a and S1). The available number of active carbon atoms at the broken edges was calculated to exponentially increase as an average grain size reduces (Fig. S2, ESI for detailed calculation). This leads to high nitrogen content at the edges, though not all active carbon atoms could react with nitrogen.

The corresponding TEM images given in Figs. S3a-S3c clearly show relatively small and uniform NGnPs with a round shape compared with starting large graphite flake (Fig. 1b). Fig. S3b reveals the edge-stripes associated with a few graphitic layers of a high crystallinity. These results, together with a dramatic increase (39 times) in the Brunauer-Emmett-Teller (BET) surface area of NGnPs (Table S1), indicate an effective and spontaneous delamination of the starting graphite into small GnPs even in the solid state by dry ballmilling. Dark field TEM image also shows similar morphology (Fig. S3c) with carbon- (Fig. S3d), nitrogen- (Fig. S3e) and oxygen-mappings (Fig. S3f) clearly showing the effective incorporation of nitrogen into the resultant NGnPs.

Elemental analyses (EA) indicate that the starting graphite has a carbon content of $99.64 \mathrm{wt} \%$ and oxygen content of $0.13 \mathrm{wt} \%$ from physisorption (Table S2) ${ }^{21}$. The resultant NGnPs have a decreased carbon content of $70.67 \mathrm{wt} \%$ and a high nitrogen content of $14.84 \mathrm{wt} \%$ (equivalent to a carbon/nitrogen atomic ratio of 5.6, see Table S2), assuring that significant amount of nitrogen has been fixed at the edges of NGnPs via the mechanochemical reaction of graphite with the inert nitrogen (Figs. 1a and S1). In addition, hydrogen and oxygen contents as much as 0.79 and $7.43 \mathrm{wt} \%$, respectively,

$\mathbf{a}$
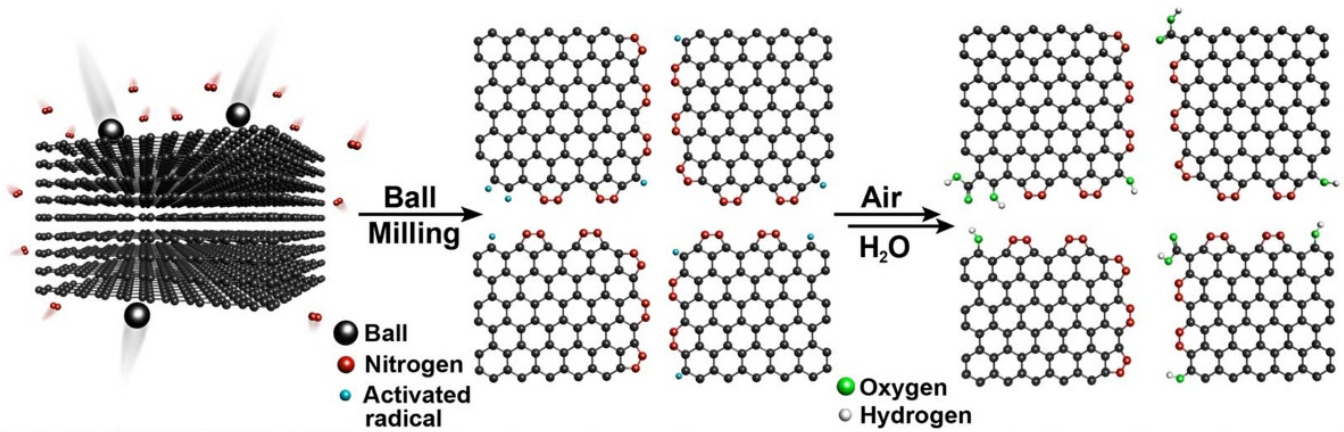

$\mathbf{b}$
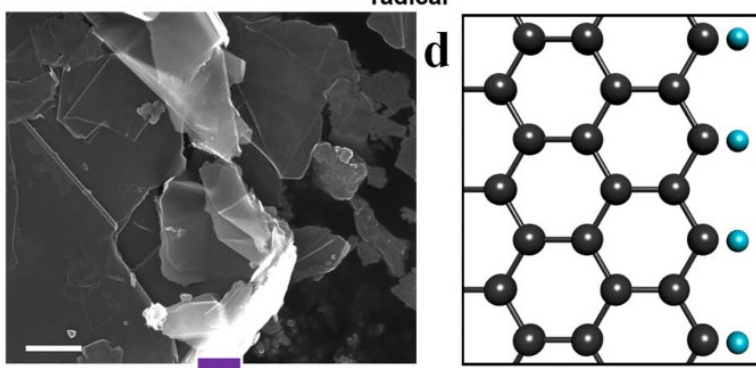

o Hydrogen
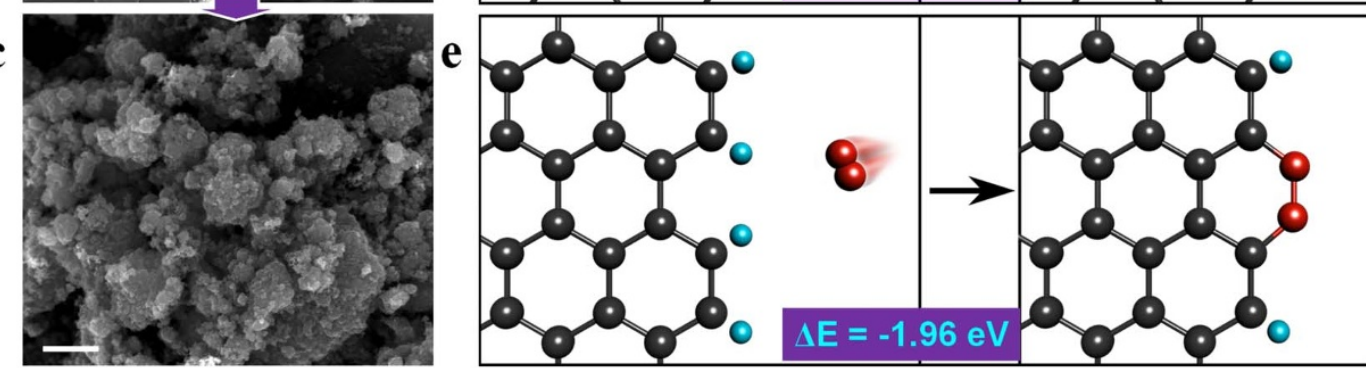

Figure 1 (a) A schematic representation of physical cracking of graphite flake in a ball-mill crusher $(500 \mathrm{~mL})$ containing stainless steel balls (500.0 g, diameter $5 \mathrm{~mm}$ ) agitated at $500 \mathrm{rpm}$ for $48 \mathrm{~h}$ in the presence of nitrogen and subsequent exposure to air moisture to produce NGnPs. SEM images: (b) starting graphite flake; (c) NGnPs after ball-milling. Scale bars are $1 \mu \mathrm{m}$. The ring formation mechanisms depending upon the cracking patterns of unzipped edges: (d) the formation of 5-membered pyrazole ring after the reaction between the active zigzag-edge carbon atoms and nitrogen; (e) the formation 6-membered pyridazine ring after the reaction between the active armchair-edge carbon atoms and nitrogen. 
were also observed arising from the remnant active carbon species, which reacted with air moisture to introduce oxygenated groups.

Fourier transform infrared spectrum of NGnPs evidently shows strong aromatic $\mathrm{C}-\mathrm{N}$ stretching peak at $1400 \mathrm{~cm}^{-1}$ and $\mathrm{C}=\mathrm{O}$ stretching peak at $1624 \mathrm{~cm}^{-1}$ (Fig. S4a), implying the presence of nitrogen-containing aromatic rings and carboxylic acid groups, respectively. In addition, the strong peak at $3400 \mathrm{~cm}^{-1}$ is attributable to the hygroscopic nature of NGnPs and crystal water associated with $\mathrm{KBr}$ used for the specimen preparation. NGnPs also display $s p^{2}$ and $s p^{3} \mathrm{C}-\mathrm{H}$ peaks at around $2927 \mathrm{~cm}^{-1}$ associated with defects created during ball-milling ${ }^{4}$. However, the corresponding spectrum for the starting graphite shows only a weak band at $1632 \mathrm{~cm}^{-1}$ characteristic of the vibration mode of adsorbed water molecules ${ }^{22}$.

The NGnP powder was further characterized by Raman spectroscopy. As expected, the starting graphite showed the $\mathrm{G}$ and $2 \mathrm{D}$ bands at 1585 and $2722 \mathrm{~cm}^{-1}$, respectively (Fig. S4b), with undetectable edge distortion and structural defects, and hence the ratio of the $\mathrm{D}$ - to G-band intensity equals zero $\left(\mathrm{I}_{\mathrm{D}} / \mathrm{I}_{\mathrm{G}}=0.0\right)$. In contrast, $\mathrm{NGnPs}$ exhibited a broad and strong $\mathrm{D}$ band over $1364 \mathrm{~cm}^{-1}$ with the $\mathrm{I}_{\mathrm{D}} /$ $\mathrm{I}_{\mathrm{G}}$ ratio of 1.0 (Fig. $\mathrm{S} 4 \mathrm{~b}$ ), indicating the grain size reduction by mechanochemical cracking (see Fig. 1c) and significant edge distortion by edge-nitrogenation (see Figs. 1a and S1).

TGA thermogram of the pristine graphite displays negligible weight loss up to $900{ }^{\circ} \mathrm{C}$ in nitrogen (Fig. S4c and Table S3). However, the NGnPs showed gradual weight loss up to $600{ }^{\circ} \mathrm{C}$, followed by a dramatic weight loss at around $723{ }^{\circ} \mathrm{C}$. Due to the hygroscopic and polar natures of pyrazole and pyridazine rings at the $\mathrm{NGnP}$ edges, the initial weight loss could be originated from bound moisture $\left(\mathrm{H}_{2} \mathrm{O}\right)$, hydrochloric acid $(\mathrm{HCl}$, see Experimental Section) and oxygenated groups ${ }^{23}$. The weight loss at $723{ }^{\circ} \mathrm{C}$ could be attributed to the loss of relatively much stable edge-heterocyclic rings (see Figs. 1a and S1). The observed gradual weight loss for NGnPs, unlike

$\mathbf{a}$

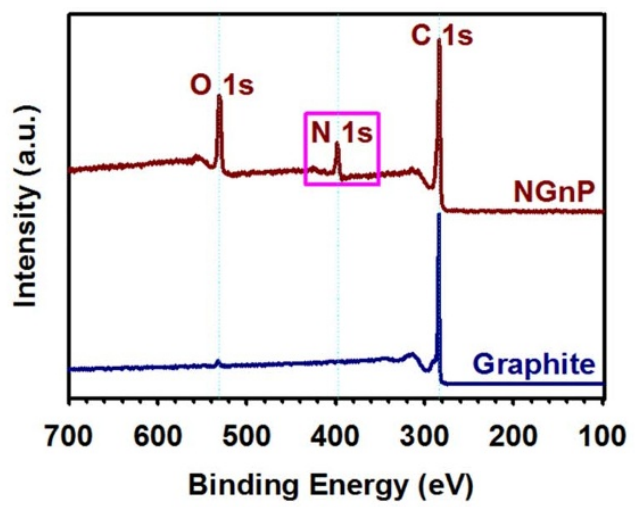

C

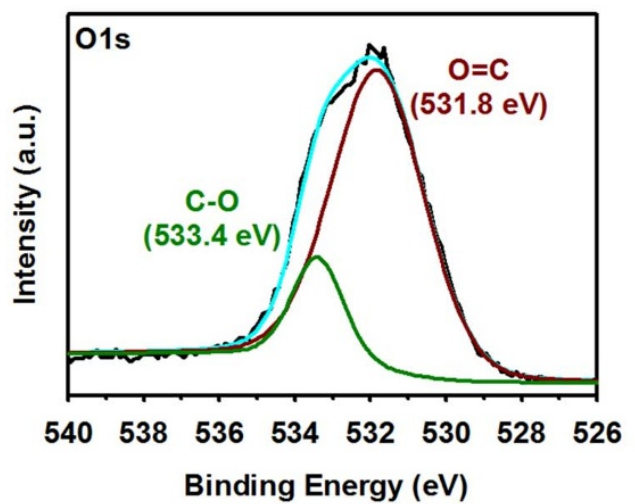

the stepwise weight loss for $\mathrm{GO}^{24}$, suggests the presence of strong inter-sheet interactions (e.g., polar interaction and H-bonding) between some of the edge-oxygenated groups to alter their decomposition temperature depending on their specific location along the edges of NGnPs. The much higher stepwise decomposition temperature $\left(\sim 723{ }^{\circ} \mathrm{C}\right)$ for $\mathrm{NGnPs}$ than that $\left(\sim 165{ }^{\circ} \mathrm{C}\right)$ for GO indicates a significantly improved overall thermal stability for the NGnPs due, most probably, to the edge-selective functionalization in NGnPs without basal plane distortion.

XRD diffraction pattern for the starting graphite shows a strong [002] peak at $26.5^{\circ}$ corresponding to a layer-to-layer $d$-spacing of $0.34 \mathrm{~nm}$ (Fig. S4d ${ }^{25}$. Compared with the starting graphite, the NGnPs displayed only a very weak [002] peak (less than $0.1 \%$ intensity) centered at $25.6^{\circ}$ (Fig. S4d, inset), indicating the occurrence of delamination of the highly edge-functionalized graphite into a few layer graphene nanoplatelets (GnPs) even in the solid state during the ball-milling and workup processes.

Further evidence for the presence of nitrogen at the edges of NGnPs comes from the XPS spectroscopic measurements. As expected, the starting graphite showed only a pronounced C 1s peak at $284.3 \mathrm{eV}$ (Fig. 2a) with a very weak, but noticeable, $\mathrm{O} 1 \mathrm{~s}$ band at $\sim 532 \mathrm{eV}$ attributable to the presence of a trace amount of physically adsorbed oxygen $^{21}$. In addition to the $\mathrm{C} 1 \mathrm{~s}$ and $\mathrm{O} 1$ s peaks, NGnPs showed the characteristic N 1s peak at $399 \mathrm{eV}$. High-resolution XPS spectra with curve fittings for the $\mathrm{C}$ 1s (Fig. 2b), O 1s (Fig. 2c), and N 1s (Fig. 2d) peaks showed that the aromatic $\mathrm{C}-\mathrm{N}$ in pyrazole (pyrrolic $-\mathrm{N}$ ) and pyridazine (pyridinic $-\mathrm{N}$ ) rings are the dominant $\mathrm{N}$ components in NGnPs. It is noteworthy that the ratio of pyrazole $(5 \mathrm{~N}) /$ pyridazine (6N) nitrogen is 2.9 (Fig. 2d and Table S3), implying that zigzag unzipping is major process ( $c f$. Fig. S1). Furthermore, XPS measurements were performed on the NGnPs having thermally annealed at 400 (below $723{ }^{\circ} \mathrm{C}$ ) and $1000{ }^{\circ} \mathrm{C}\left(\right.$ above $723^{\circ} \mathrm{C}$ ) for 30 min under

b

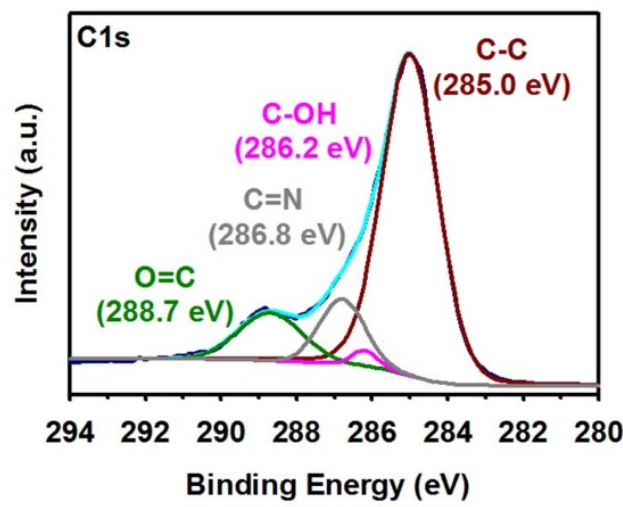

d

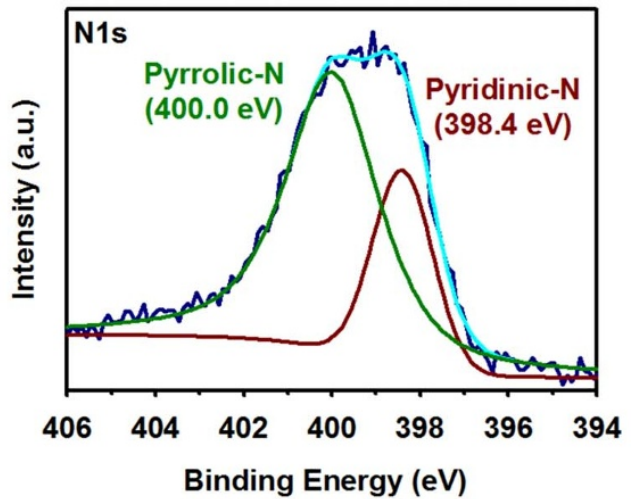

Figure 2 2 (a) XPS survey spectra of the pristine graphite and the as-prepared NGnPs. High-resolution XPS spectra of NGnPs: (b) C 1s; (c) O 1s; (d) N 1 s. 
argon atmosphere to assure the origins of the weight losses observed in TGA (see Fig. S4c). The XPS survey of the heat-treated NGnPs at 400 ${ }^{\circ} \mathrm{C}$ shows no obvious change in the intensities of both $\mathrm{O} 1 \mathrm{~s}$ and $\mathrm{N} 1 \mathrm{~s}$ peaks (Fig. S5 and Table S3), implying that nitrogen atoms were covalently incorporated into aromatic rings. For the NGnPs heattreated at $1000{ }^{\circ} \mathrm{C}$, the intensities of both the $\mathrm{O} 1 \mathrm{~s}$ and $\mathrm{N}$ 1s peaks were dramatically decreased (Fig. S6 and Table S3). Therefore, the early gradual weight loss observed in the TGA measurements should be related to the unbound volatile substances, due to hygroscopic and polar natures of NGnPs, whereas the corresponding weight loss at 723 ${ }^{\circ} \mathrm{C}$ is due to the loss of relatively stable edge-heterocyclic rings. Interestingly, the ratios of $5 \mathrm{~N} / 6 \mathrm{~N}$ nitrogen were gradually reduced from 2.9 to 2 and 1.5 for the NGnPs heat-treated at 400 and 1000 ${ }^{\circ} \mathrm{C}$, respectively, suggesting that the 5 -membered pyrazole ring is less stable than the 6-membered pyridazine ring (Figs. 2d, S5d, S6d and Table S3). Overall, the XPS results are in accordance with the FT-IR (see Fig. S4a) and TGA results (see Fig. S4c), supporting the mechanism shown in Figs. 1a and S1.

The grain size reduction for an entropic gain (see Figs. 1b and 1c) and the edge-selective functionalization (nitrogenation and subsequent oxygenation) for an enthalpic enhancement could greatly improve solubility of the NGnPs. Indeed, NGnPs were found to be readily dispersible not only in polar protic solvents, such as neutral water, basic water (containing ammonium hydroxide), methanol and isopropyl alcohol, but also polar aprotic solvents, including acetone, $\mathrm{N}, \mathrm{N}$-dimethylacetamide (DMAc), $\mathrm{N}, \mathrm{N}$-dimethylformamide (DMF) and $N$-methyl-2-pyrrolidone (NMP) (Fig. S7). Among all the solvents tested, DMAc was found to be the best for dispersing NGnPs into a stable dispersion with similar Zeta-potential values of -42.4 and $-31.9 \mathrm{mV}$ at the concentrations of 0.02 and $0.10 \mathrm{mg} / \mathrm{mL}$ (Figs. S7c, S7d and Table S4), respectively. It is well known that a Zeta-potential value either more negative or positive than $\pm 30 \mathrm{mV}$ is sufficient to ensure good dispersion stability via charge repulsion ${ }^{26}$.

\section{Discussion}

Having assured the structure and solubility of NGnPs, we further investigated their applications as electrode materials for energy conversion in dye-sensitized solar cells (DSSCs) and fuel cells (FCs). To start with, we performed density functional calculations, using the Vienna $A b$ initio Simulation Package (VASP) ${ }^{27,28}$, to analyze the stability and electronic structure of the nitrogenated edges. The plane-wave basis set with an energy cut-off of $400 \mathrm{eV}$, and the PBE-type gradient-corrected exchange-correlation potential were employed ${ }^{29}$. The passivation of the active carboradicals with the uncleaved $\mathrm{N}_{2}$ resulted in 5-membered pyrazole (Fig. 3a) and 6-membered pyridazine (Fig. 3c) rings at the zigzag- and armchair-shaped broken edges, respectively. As shown in Figs. $3 \mathbf{b}$ and $3 d$, the lone-pair states of nitrogen in-plane orbitals constituted the distinctive edge-localized bands just below the Fermi level. More remarkably, however, the $\pi$ states of graphene are well preserved including the nitrogen $p_{z}$-orbitals in the conjugated networks. These unique edge-localized band structures, in conjunction with the undamaged basal plane of NGnPs, can lead to advantageous catalysts that surpass the performance of Pt for DSSC and FC applications described below.

For construction of DSSCs, a uniform NGnP film on fluorine (F)doped tin oxide $\left(\mathrm{SnO}_{2}, \mathrm{FTO}\right) /$ glass was deposited by an electrostatic spray (e-spray) deposition technique from an NGnPs dispersion in 2-propanol (Fig. S8a). SEM images of the bare FTO (Fig. S8b) and NGnP deposited FTO (NGnP-FTO) (Fig. S8c) exhibit different surface morphologies. DSSC with $O$-alkylated-JK-225-sensitizer ${ }^{30}$ and HC-A as a coadsorbent ${ }^{31}$ was fabricated using the resultant NGnPFTO as a counter electrode (CE). For comparison purpose, DSSC with Pt-FTO CE was also fabricated. As judged by the peak-to-peak separations $\left(E_{\mathrm{PP}}\right)$ and current densities, the cyclic voltammograms $(\mathrm{CV})$ of NGnP-FTO electrode for the $\mathrm{Co}(\mathrm{bpy})_{3}{ }^{3+/ 2+}$ redox couple showed very similar curve shape with apparently much higher $\mathbf{a}$
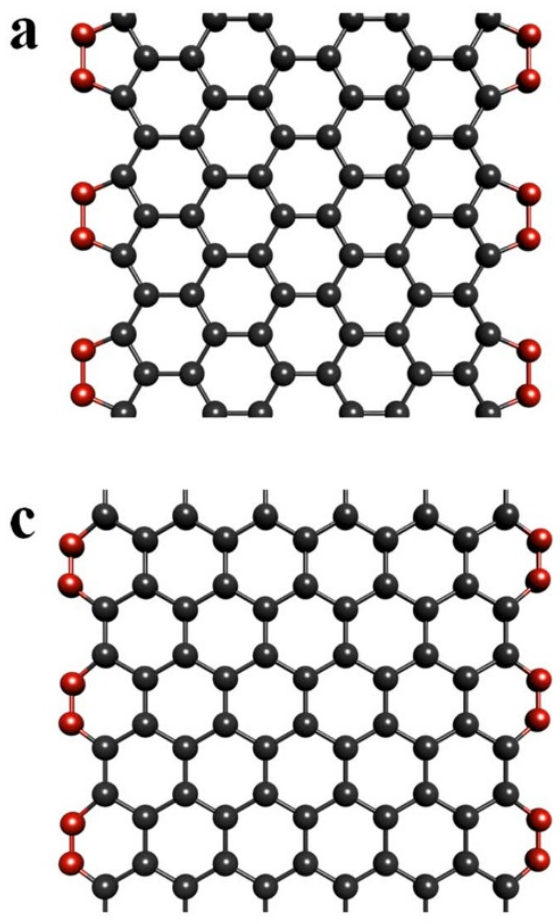

b
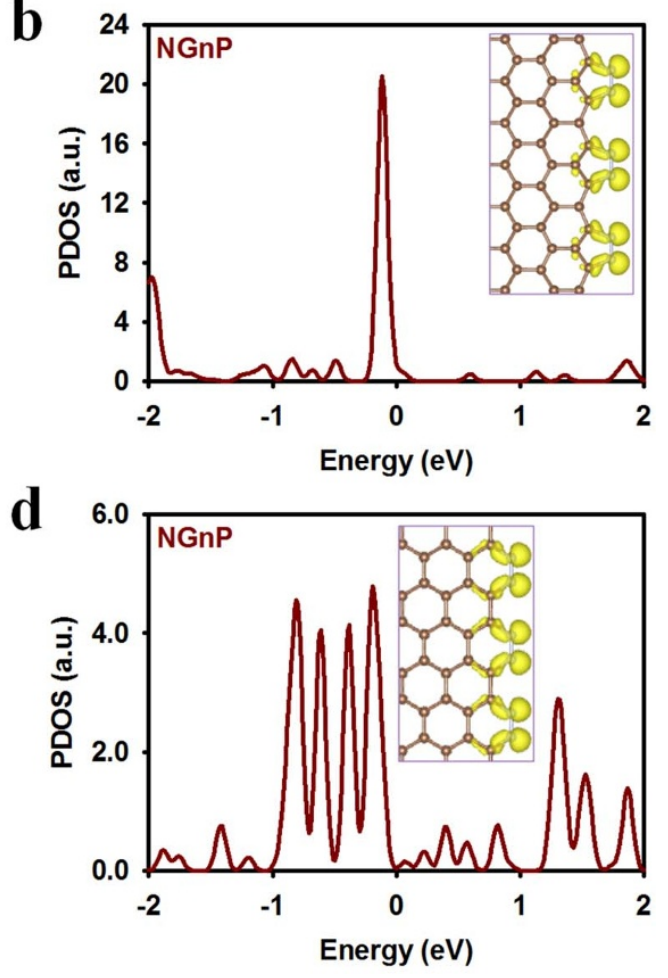

Figure $3 \mid$ The NGnP with edge 5-membered pyrazole rings. (a) the model structure; (b) the PDOS for N atoms. The NGnP with edge 6-membered pyridazine rings: (c) the model structure; (d) the PDOS for $\mathrm{N}$ atoms. The isosurfaces of the squared Kohn-Sham orbitals of edge-localized states are shown in the insets. 
electrocatalytic activity than that of the Pt-FTO electrode (Fig. S9a). In addition, the oxidation peak of NGnP-FTO CE located at less positive potential than that of the Pt-FTO CE electrode, implying better electrocatalytic performance for the former. The higher current density observed for the NGnP-FTO CE with respect to the PtFTO CE could be attributed to an efficient charge transfer resulted from the sufficient nitrogen doping $(\sim 15 \%$ by EA, see Table S2).

On the basis of promising CV results (Fig. S9a), the electrocatalytic activities of the sample electrodes were further examined by electrochemical impedance spectroscopy (EIS) using symmetrical dummy cells (Fig. S9b ${ }^{32}$. The EIS results could be fitted by using a Randles-type circuit (Fig. 4a), where $R_{\mathrm{S}}$ is the Ohmic serial resistance, $R_{\mathrm{CT}}$ is the charge transfer resistance at the interface between the electrode surface and the electrolyte, $Z_{\mathrm{W}}$ is the Nernst diffusion impedance in the bulk electrolyte solution between the two identical electrodes, and CPE is a constant phase element describing the deviation from the ideal capacitance due to the surface roughness of the electrodes $^{33}$. As seen in Fig. 4b, both impedance spectra of NGnP and Pt exhibited two distinct semicircles, while semicircles in between them at low frequency regions are no significant difference, e.g., diffusion coefficients of $\mathrm{Co}(\mathrm{bpy})_{3}{ }^{3+}$ in the NGnP- and Pt-FTO dummy cells were almost similar values, which were found to be $4.5 \times 10^{-6}$ and $3.2 \times 10^{-6} \mathrm{~cm}^{2} / \mathrm{s}$, respectively, and other EIS parameters were summarized in Table S5. The result implies that ionic diffusion in the bulk electrolyte solution is independent of the electrodes (i.e., this parameter is invariant with the electrocatalytic activities of the electrodes). However, the $R_{\mathrm{CT}}$ of the NGnP-FTO is lower than that of the Pt-FTO. The result provides strong evidence that the intrinsic catalytic activity of the NGnP-FTO is much higher than that of the Pt-FTO.

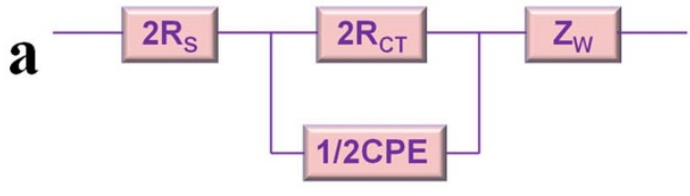

b

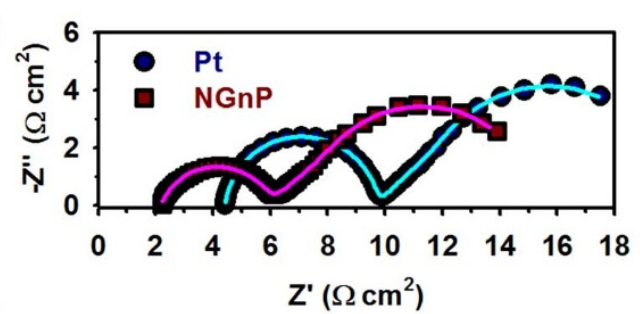

d

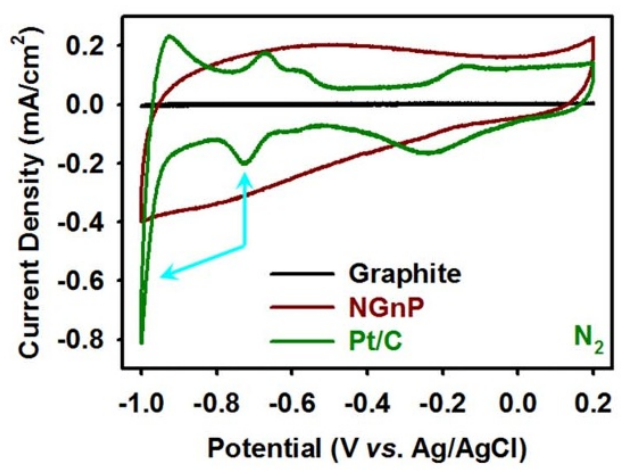

On the basis of the in-depth evaluation of the NGnP CE described in Fig. S9 and corresponding explanation, we further investigated the photocatalytic activities of the NGnP electrodes as the CE in actual devices in $\mathrm{Co}(\text { bpy })_{3}$-mediated solar cells. The NGnP-based DSSC outperformed its Pt counterpart (Fig. $4 \mathrm{c}$ and Table S6). The Pt-based DSSC exhibited a short circuit current $\left(J_{\mathrm{sc}}\right)$ of $14.113 \mathrm{~mA} / \mathrm{cm}^{2}$, open circuit voltage $\left(V_{\mathrm{oc}}\right)$ of $886 \mathrm{mV}$, fill factor $(\mathrm{FF})$ of $70.8 \%$, and an overall power conversion efficiency (PCE) of $8.85 \%$. The DSSC with the NGnP-based DSSC showed an even higher $V_{\mathrm{oc}}$ of $890 \mathrm{mV}$, FF of $74.1 \%$ and PCE of $9.34 \%$, but a similar $J_{\mathrm{sc}}$ of $14.162 \mathrm{~mA} / \mathrm{cm}^{2}$. On the basis of the EIS measurements (Fig. S10a) and curve fittings with an equivalent circuit (Fig. S10b), the $R_{\mathrm{CT}}$ value of the DSSC with the NGnP-FTO CE is much lower than that of Pt-FTO CE (Table S7), and it might allow for an increase in FF of DSSC. Clearly, therefore, the NGnP CE with a higher electrocatalytic activity, less $R_{\mathrm{CT}}$ and better stability outperformed the Pt CE in DSSCs.

To investigate the electrocatalytic activity of NGnPs for oxygen reduction in fuel cells (FCs), we further measured the reduction capability of the NGnPs on glassy carbon (GC) in $\mathrm{N}_{2}$ - and $\mathrm{O}_{2}$-saturated alkaline electrolytes $(0.1 \mathrm{M}$ aq. $\mathrm{KOH}$ solution). The pristine graphite and commercially available Pt/C (Vulcan XC-72R) with the same mass loadings on GC were also measured as references. While the NGnP/GC electrode showed featureless $\mathrm{CV}$ in the $\mathrm{N}_{2}$-saturated $0.1 \mathrm{M}$ aq. $\mathrm{KOH}$ solution (Fig. 4d), it exhibited an obvious oxygen reduction peak in the corresponding $\mathrm{O}_{2}$-saturated electrolyte (Fig. 4e). The pristine graphite showed a single cathodic reduction peak at $-0.43 \mathrm{~V}$ with a current density of $-0.19 \mathrm{~mA} \mathrm{~cm}^{-2}$ in the $\mathrm{O}_{2}$ saturated $0.1 \mathrm{M}$ aq. $\mathrm{KOH}$ solution. The corresponding cathodic reduction peak for the NGnPs was positively shifted to $-0.28 \mathrm{~V}$ with a current density of $-0.54 \mathrm{~mA} \mathrm{~cm}{ }^{-2}$. The $\mathrm{Pt} / \mathrm{C}$ exhibited a single
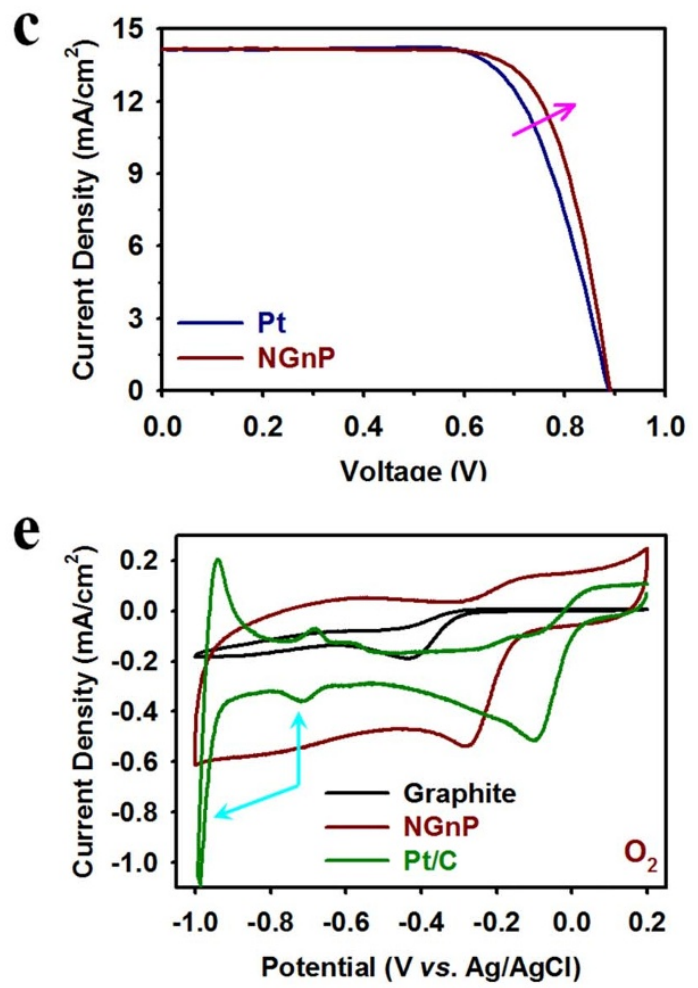

Figure $4 \mid$ (a) Equivalent circuit diagram for fitting the EIS data. (b) Nyquist plots of EIS spectra measured at $0 \mathrm{~V}$ from $10^{6} \mathrm{~Hz}$ to $0.1 \mathrm{~Hz}$ on dummy cells of Pt and NGnP, and solid lines are fitted curves. (c) Current-voltage characteristics of DSSCs with the Pt-FTO and NGnP-FTO CEs under simulated AM 1.5 light. The $\mathrm{TiO}_{2}$ film thickness and active area are $9(6+3) \mu \mathrm{m}$ and $0.16 \mathrm{~cm}^{2}$ with a black metal mask, respectively. Cyclic voltammograms (CV) of samples on glassy carbon (GC) electrodes with a scan rate of $0.01 \mathrm{~V} / \mathrm{s}$ : (d) in $\mathrm{N}_{2}$-saturated $0.1 \mathrm{M}$ aq. $\mathrm{KOH}$ solution; (e) in $\mathrm{O}_{2}$ saturated $0.1 \mathrm{M}$ aq. $\mathrm{KOH}$ solution. Sky blue arrows indicate the contributions of hydrogen evolution at around $-0.7 \mathrm{~V}$ and out of Pt limiting potential $(-0.8 \mathrm{~V})$. 
cathodic reduction peak at $-0.10 \mathrm{~V}$ with a current density of $-0.52 \mathrm{~mA} \mathrm{~cm}^{-2}$. The current density from NGnP is over 2.8 times that of the pristine graphite and comparable to that of $\mathrm{Pt} / \mathrm{C}$. Furthermore, the NGnP electrode has high capacitances of 126.6 and $161.3 \mathrm{~F} \mathrm{~g}^{-1}$ with superb cycle stabilities in both $\mathrm{N}_{2}-$ and $\mathrm{O}_{2}$ - saturated electrolytes, respectively (Figs. S11-S14 and Table S8), which can be attributed to the relatively high BET surface area (Table S1) and structural stability of NGnPs (see Fig. S4c).

To gain further study the kinetics of the NGnP-catalyzed ORR process, the rotating disk electrode ( $\mathrm{RDE}$ ) measurements were performed in an $\mathrm{O}_{2}$-saturated, $0.1 \mathrm{M}$ aq. $\mathrm{KOH}$ solution at various rotating speeds and a constant scan rate of $0.1 \mathrm{~V} \mathrm{~s}^{-1}$. As shown in Figs. S14a-14c, the diffusion current densities increased with increasing the rotating rates, while the onset potentials remained almost constant. The number of electron transfers $(n)$ per $\mathrm{O}_{2}$ molecule involved in the ORR process can be calculated from the slope of the KouteckyLevich equation (see Experimental section in ESI) (Figs. S14d-14f). As summarized in Fig. S15 and Table S9, while the number of transferred electrons for the pristine graphite is close to the classical twoelectron process $(n \sim 2.0)$, the ORR processes at the NGnP and $\mathrm{Pt}$ electrodes are an ideal four-electron process $(n \sim 4.0)$. Evidently, therefore, the edge-nitrogenation played an important role to significantly improve the ORR performance of NGnPs (Table S10).

In summary, we have developed a simple and eco-friendly ballmilling process to efficiently exfoliate the pristine graphite directly into edge-nitrogenated graphene nanoplatelets (NGnPs). A plausible reaction mechanism for the direct nitrogen fixation $(\mathrm{C}-\mathrm{N}$ bond formation) by ball-milling process in the presence of nitrogen was proposed and confirmed by various microscopic and spectroscopic measurements. The resultant NGnPs were demonstrated to be highly dispersible in various polar solvents suitable for solution processes. The solution-cast NGnP electrodes exhibited superior catalytic properties in DSSCs and FCs with respect to the precious Pt counterparts. Hence, direct nitrogen fixation developed in this study using ballmilling technique could be regarded as a general approach toward low-cost, mass production of NGnPs for multifunctional materials and devices applications.

\section{Methods}

Preparation of NGnPs. NGnPs were prepared by ball-milling the pristine graphite flake in a planetary ball-mill machine (Pulverisette 6, Fritsch) in the presence of nitrogen $\left(\mathrm{N}_{2}\right)$. The pristine graphite $(5.0 \mathrm{~g}$, Alfa Aesar, natural graphite, 100 mesh $(<$ $150 \mu \mathrm{m}), 99.9995 \%$ metals basis, Lot\#14735) was placed into a stainless steel ball-mill capsule $(500 \mathrm{~mL})$ containing stainless steel balls $(500.0 \mathrm{~g}$, diameter $5 \mathrm{~mm})$. The capsule was sealed and charged with $\mathrm{N}_{2}$ (8 bar of cylinder pressure) after five charging-discharging cycles and then it was fixed in the planetary ball-mill machine and agitated at $500 \mathrm{rpm}$ for $48 \mathrm{~h}$. The resultant product was Soxhlet extracted with methanol and $1 \mathrm{M}$ aq. $\mathrm{HCl}$ solution to get rid of metallic impurities, if any. Further repeated treatments with ethylenediaminetetraacetic acid (EDTA), concentrated ammonium hydroxide $\left(\mathrm{NH}_{4} \mathrm{OH}\right)$ and $1 \mathrm{M}$ aq. $\mathrm{HCl}$ solution were carried until there is no metallic residue detected by XPS. Final product was freeze-dried at $-120^{\circ} \mathrm{C}$ under a reduced pressure $\left(0.05 \mathrm{mmHg}\right.$ ) for $48 \mathrm{~h}$ to yield $5.67 \mathrm{~g}$ (at least $0.67 \mathrm{~g} \mathrm{~N}_{2}$ uptake) of dark black powder, implying the occurrence of nitrogen-fixation to the ball milled graphite.

1. Postgate, J. Nitrogen Fixation. (Cambridge University Press, Cambridge UK, 1998).

2. Bothe, H., Ferguson, S. \& Newton, W. E. Biology of the nitrogen cycle. (Elsevier, Amsterdam, 2007).

3. Fryzuk, M. D. \& Johnson, S. A. The continuing story of dinitrogen activation. Coord. Chem. Rev. 200, 379-409 (2000).

4. Jeon, I. Y. et al. Edge-carboxylated graphene nanosheets via ball milling. Proc. Natl. Acad. Sci. USA 109, 5588-5593 (2012).

5. Jeon, I. Y. et al. Large-Scale production of edge-selectively functionalized graphene nanoplatelets via ball milling and their use as metal-free electrocatalysts for oxygen reduction reaction. J. Am. Chem. Soc. 135, 1386-1393 (2013).

6. O’Regan, B. \& Grätzel, M. A low-cost, highefficiency solar cell based on dyesensitized colloidal $\mathrm{TiO}_{2}$ films. Nature 353, 737-740 (1991).

7. Steele, B. C. H. \& Heinzel, A. Materials for fuel-cell technologies. Nature 414, 345-352 (2001).
8. Hinsch, A. et al. Long-term stability of dye-sensitised solar cells. Prog. Photovolt Res. Appl. 9, 425-438 (2001).

9. Oetjen, H. F., Schmidt, V., Stimming, U. \& Trila, F. Performance data of a proton exchange membrane fuel cell using $\mathrm{H}_{2} / \mathrm{CO}$ as fuel gas. J. Electrochem. Soc. 143, 3838-3842 (1996).

10. Murakami, T. N. et al. Highly efficient dye-sensitized solar cells based on carbon black counter electrodes. J. Electrochem. Soc. 153, A2255-A2261 (2006).

11. Jia, R. et al. Synthesis of highly nitrogen-doped hollow carbon nanoparticles and their excellent electrocatalytic properties in dye-sensitized solar cells. J. Mater. Chem. 20, 10829-10834 (2010).

12. Jia, R. et al. Synthesis of highly nitrogen-doped hollow carbon nanoparticles and their excellent electrocatalytic properties in dye-sensitized solar cells. J. Mater. Chem. 20, 10829-10834 (2010).

13. Han, J. et al. Water-soluble polyelectrolyte-grafted multiwalled carbon nanotube thin films for efficient counter electrode of dye-sensitized solar cells. ACS Nano 4, 3503-3509 (2010).

14. Hong, W. et al. Transparent graphene/PEDOT-PSS composite films as counter electrodes of dye-sensitized solar cells. Electrochem. Commun. 10, 1555-1558 (2008).

15. Choi, H. et al. Graphene counter electrodes for dye-sensitized solar cells prepared by electrophoretic deposition. J. Mater. Chem. 21, 7548-7551 (2011).

16. Roy-Mayhew, J. D., Bozym, D. J., Punckt, C. \& Aksay, I. A. Functionalized graphene as a catalytic counter electrode in dye-sensitized solar cells. ACS Nano 4, 6203-6211 (2010).

17. Xue, Y. et al. Nitrogen-doped graphene foams as metal-free counter electrodes in high-performance dye-sensitized solar cells. Angew. Chem. Int. Ed. 51, 12124-12127 (2012).

18. Yang, L. et al. Boron-doped carbon nanotubes as metal-free electrocatalysts for the oxygen reduction reaction. Angew. Chem. Int. Ed. 123, 7270-7273 (2011).

19. Hummers Jr, W. S. \& Offeman, R. E. Preparation of graphitic oxide. J. Am. Chem. Soc. 80, 1339-1339 (1958).

20. Gong, K. et al. Nitrogen-doped carbon nanotube arrays with high electrocatalytic activity for oxygen reduction. Science 323, 760-764 (2009).

21. Collins, P. G., Bradley, K., Ishigami, M. \& Zettl, A. Extreme oxygen sensitivity of electronic properties of carbon nanotubes. Science 287, 1801-1804 (2000).

22. Stankovich, S., Piner, R. D., Nguyen, S. B. T. \& Ruoff, R. S. Synthesis and exfoliation of isocyanate-treated graphene oxide nanoplatelets. Carbon 44, 3342-3347 (2006).

23. Stankovich, S. et al. Synthesis of graphene-based nanosheets via chemical reduction of exfoliated graphite oxide. Carbon 45, 1558-1565 (2007).

24. Park, S. \& Ruoff, R. S. Chemical methods for the production of graphenes. Nat. Nanotechnol. 4, 217-224 (2009).

25. Li, Z. Q. et al. X-ray diffraction patterns of graphite and turbostratic carbon. Carbon 45, 1686-1695 (2007)

26. Everett, D. H. Basic principles of colloid science. (Royal Society of Chemistry, London, 1988).

27. Hohenberg, P. \& Kohn, W. Inhomogeneous electron gas. Phys. Rev. 136, B864-B871 (1964).

28. Kresse, G. \& Furthmüller, J. Efficiency of ab-initio total energy calculations for metals and semiconductors using a plane-wave basis set. Comput. Mater. Sci. 6, 15-50 (1996).

29. Perdew, J. P., Burke, K. \& Ernzerhof, M. Generalized gradient approximation made simple. Phys. Rev. Lett. 77, 3865-3868 (1996).

30. Lim, K. et al. Enhancing the performance of organic dye-sensitized solar cells via a slight structure modification. J. Phys. Chem. C 115, 22640-22646 (2011).

31. Song, B. J. et al. A desirable hole-conducting coadsorbent for highly efficient dyesensitized solar cells through an organic redox cascade strategy. Chem. Eur. J. 17, 11115-11121 (2011).

32. Fang, X. et al. Effect of the thickness of the Pt film coated on a counter electrode on the performance of a dye-sensitized solar cell. J. Electroanal. Chem. 570, 257-263 (2004).

33. Wang, G., Xing, W. \& Zhuo, S. Application of mesoporous carbon to counter electrode for dye-sensitized solar cells. J. Power Sources 194, 568-573 (2009).

\section{Acknowledgements}

This research was supported by World Class University (WCU), US-Korea NBIT, Mid-Career Researcher (MCR), Converging Research Center (CRC) and Basic Research Laboratory (BRL) programs through the National Research Foundation (NRF) of Korea funded by the Ministry of Education, Science and Technology (MEST), US Air Force Office of Scientific Research through Asian Office of Aerospace R\&D (AFOSR-AOARD), and AFOSR (FA9550-12-1-0037, FA-9550-12-1-0069).

\section{Author contributions}

J.-B.B. conceived the reaction system and oversaw all the research phases. I.-Y.J., H.-J.C. M.J.J. conducted experiments. I.T.C., K.L., J.C.K., D.S., S.-M.J., J.-M.S. and M.-J.K. carried out the characterizations. N. P. was involved in the $A b$ initio study of the new material by DFT. M.J.J., J.K., J.-J.L. and H.K.K. supervised solar cell study. J.-B.B., N.P. and L.D. wrote the paper and discussed the results. All authors contributed and commented on this manuscript. 


\section{Additional information}

Supplementary information accompanies this paper at http://www.nature.com/ scientificreports

Competing financial interests: The authors declare no competing financial interests.
How to cite this article: Jeon, I.-Y. et al. Direct nitrogen fixation at the edges of graphene nanoplatelets as efficient electrocatalysts for energy conversion. Sci. Rep. 3, 2260; DOI:10.1038/srep02260 (2013)

(c) (i) $(9$ This work is licensed under a Creative Commons Attribution-

cc. ${ }_{\mathrm{BY}} \mathrm{NC}$ No NonCommercial-NoDerivs 3.0 Unported license. To view a copy of this license, visit http://creativecommons.org/licenses/by-nc-nd/3.0 